\title{
UNIVERSITYOF
}

FORWARD

THINKING

WESTMINSTER用

WestminsterResearch

http://www.westminster.ac.uk/westminsterresearch

Viewpoint: Urban Design Pedagogy

Roberts, M.

This is an Accepted Manuscript of an article published by Taylor \& Francis in Journal of Urban Design, 21 (5), 567-569, 2016 The final definitive version is available online:

https://dx.doi.org/10.1080/13574809.2016.1220150

The WestminsterResearch online digital archive at the University of Westminster aims to make the research output of the University available to a wider audience. Copyright and Moral Rights remain with the authors and/or copyright owners.

Whilst further distribution of specific materials from within this archive is forbidden, you may freely distribute the URL of WestminsterResearch: ((http://westminsterresearch.wmin.ac.uk/).

In case of abuse or copyright appearing without permission e-mail repository@westminster.ac.uk 


\section{Urban Design Pedagogy}

Urban design education may not have a long history in the English speaking world, but this rich collection of papers demonstrates that a lack of an established tradition may be an advantage. These articles demonstrate sophistication and freshness but with many common attributes. Collectively, there is a wealth of information and references to a range of academic literature on the processes of teaching urban design and planning in higher education. Any candidate embarking on the arduous process of acquiring a Postgraduate Certificate in Teaching in Higher Education - which will soon be a mandatory requirement in UK HEl's - would be advised to comb the bibliographies of these excellent articles. There is a desire, too, to grapple with 'real' world problems, in the context of our globalised world. This engagement demands an interface, or interaction with complexity, whether it be a multiscalar approach to the city, the multi-dimensional nature of urban issues or situations of conflict between institutions, cultures or individuals. Such complexity carries the implication of interdisciplinarity, going beyond the bounding of the built environment disciplines of architecture, planning and landscape architecture normally found in urban design. Neuman's and Moudon's papers discuss separate approaches to interdisciplinarity, the first through a sharing and meta-view of issues in community based projects, the second through a highly specialised and dedicated 'laboratory' or research institute setting.

The emphasis on the value of in-depth community participation, highlighted in three of the papers, provides a refreshing challenge to the recent promotion of MOOCs and TEDs as the new way forward for university education. Moving accounts are given of meaningful interaction between students and local residents, leading in some cases to changes in world view for both parties. There are impacts on local plans, policies and projects too. Kallus' project in an Arab neighbourhood in Haifa and Loukatou-Sideris's in Los Angeles both see residents and students working together to lobby the local authority and create new spaces.

The potential of new information technology is not neglected. Big data provides its own challenges, needing much time to absorb and sift. At the moment it seems that urban design is in its infancy in incorporating this new paradigm into its practice and it may be that $\mathrm{PhD}$ research and postgraduate projects can help to move the field forward. At a more individual level, the advent of the smartphone has opened up many possibilities for using photography and video in teaching and learning, especially as many students are more technically proficient than their tutors. Lim, Azevedos and Cooper's paper helps to show how new technologies can be incorporated throughout an undergraduate curriculum, supporting learning and allowing students with more limited language skills to internalise theory through reflection and documentation.

Which last point leads on to an issue that has been slowly developing over the last decade. Globalisation and a movement towards a mass higher education system have radically changed the constitution of the student body in certain institutions in the UK. An implicit assumption of a local elite of students pursuing full time courses, each sharing a world view and a particular set of experiences, no longer applies. Urban design tends to be taught at postgraduate level. Mature part-time students, engaged in 'real world' urban design and planning outside their courses now come to university and study alongside their full-time counterparts. There are even some students, not enough, from deprived backgrounds, or from minority ethnic groups in society who have suffered real discrimination in the course of their lives. This has led to academics facing a diverse, heterogeneous set of students in any one class.

One the one hand this provides much fertile ground for exchange, on the other it means that there are no common cultural assumptions and implicit knowledge has to be explained, including humorous asides. A new challenge is to harness the diverse experience of students who come from different cultures and continents, to respect their backgrounds and 
to facilitate a more structured reflection on the different currents in urbanism as played out across the world. Much of the literature in urban design is derived from an Anglo-American perspective. Rapid urbanisation in Asia, Latin America and the Middle East and the need to teach content that will be relevant to students from is starting to rebalance urban design commentary. We are now seeing a body of literature that addresses urban design in China and the Middle East. It is to be hoped more will follow.

That the UK currently enjoys diversity in its student body is of course, a product of a neoliberalist agenda, which sees higher education system as a commodity to be marketed and sold rather than a public good provided for its citizens. While, as discussed above, this has benefits with regard to the internationalisation of the student body, one of the consequences is a requirement to produce the components of degree programmes in roughly equivalent packages. These packages need to be described and proscribed, so that they can be purchased or swapped or integrated with other packages on similar courses. Academics have had to professionalise and discover a whole new set of discourses, vocabulary and theory to describe what they do as teachers. The deep reflection evident in this collection demonstrates the strength of this approach. Yet each of the articles on group project teaching refers to the extra work involved for both students and staff. Students also commented that the extra work had some impact and maybe had even detracted, from their ability to devote time to other parts of their degree programmes. Constraints on time for staff limit what can be achieved through the type of ground-breaking case studies explored in this special issue. Staff setting out on their careers have to weigh up the competing priorities facing them as they seek to progress through the academic hierarchy. Fortunately, as urban design develops as a discipline, research on pedagogical approaches will 'count' towards promotion and contribute to the development of the discipline. 